\title{
8
}
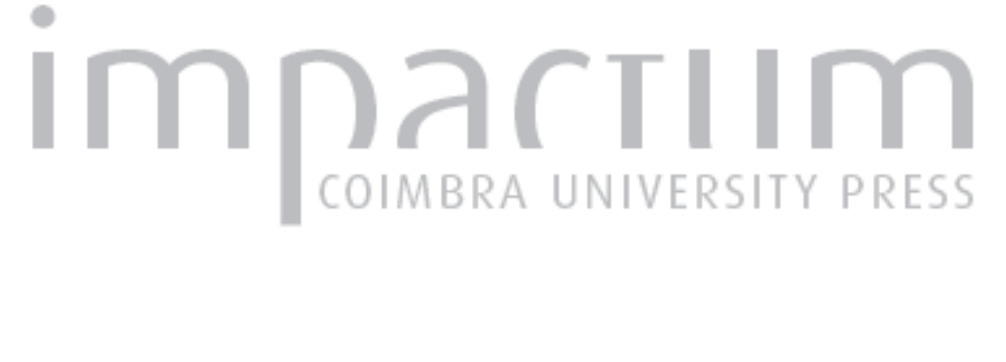

\section{Risco de incêndio numa fossa de resíduos sólidos}

Autor(es): $\quad$ Ferreira, Emanuel; Rodrigues, João Paulo C.; Coelho, Leça

Publicado por: Associação Portuguesa de Riscos, Prevenção e Segurança

URL persistente:

URI:http://hdl.handle.net/10316.2/36081

DOI:

DOI:http://dx.doi.org/10.14195/1647-7723_18_25

Accessed : $\quad$ 26-Apr-2023 10:30:21

A navegação consulta e descarregamento dos títulos inseridos nas Bibliotecas Digitais UC Digitalis, UC Pombalina e UC Impactum, pressupõem a aceitação plena e sem reservas dos Termos e Condições de Uso destas Bibliotecas Digitais, disponíveis em https://digitalis.uc.pt/pt-pt/termos.

Conforme exposto nos referidos Termos e Condições de Uso, o descarregamento de títulos de acesso restrito requer uma licença válida de autorização devendo o utilizador aceder ao(s) documento(s) a partir de um endereço de IP da instituição detentora da supramencionada licença.

Ao utilizador é apenas permitido o descarregamento para uso pessoal, pelo que o emprego do(s) título(s) descarregado(s) para outro fim, designadamente comercial, carece de autorização do respetivo autor ou editor da obra.

Na medida em que todas as obras da UC Digitalis se encontram protegidas pelo Código do Direito de Autor e Direitos Conexos e demais legislação aplicável, toda a cópia, parcial ou total, deste documento, nos casos em que é legalmente admitida, deverá conter ou fazer-se acompanhar por este aviso.

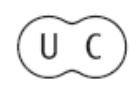




\section{territorium}

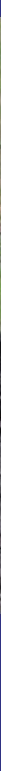

\section{Afirmar as Ciências Cindínicas}

Revista da Associação Portuguesa de Riscos, Prevenção e Segurança 
territorium 18, 2011, 263-269

journal homepage: http://www.nicif.pt/riscos/Territorium/numeros_publicados

RISCO DE INCÊNDIO NUMA FOSSA DE RESÍDUOS SÓLIDOS*

Emanuel Ferreira

Serviço Regional de Protecção Civil da Madeira emanuel.ferreira@procivmadeira.pt

João Paulo C. Rodrigues

Faculdade de Ciências e Tecnologia da Universidade de Coimbra jpaulocr@dec.uc.pt

Leça Coelho

Laboratório Nacional de Engenharia Civil alcoelho@lnec.pt

\section{RESUMO}

Neste artigo é analisado o risco de incêndio numa instalação de tratamento de resíduos sólidos urbanos, nomeadamente ao nível da sua fossa de deposição desses resíduos. Foram realizadas simulações do desenvolvimento do incêndio usando um modelo de duas zonas, o Consolidated Model of Fire and Smoke Transport (CFAST) e um modelo de campo, o Fire Dynamics Simulator and Smokeview (FDS-SMV), ambos do National Institute of Standards and Technology (NIST), sendo os resultados analisados e discutidos.

Palavras chave: Risco, incêndio, modelo, campo, zona.

\section{RESUMEN}

Riesgo de incendio en una fosa de residuos sólidos - En esto artículo se analiza el riesgo de incendio de una planta de tratamiento de residuos sólidos urbanos, en particular en la fosa de deposición de los residuos. Se llevaron a cabo simulaciones del desarrollo del incendio mediante el uso de un modelo de dos zonas, el Consolidated Model of Fire and Smoke Transport (CFAST) y un modelo de campo, el Fire Dynamics Simulator and Smokeview (FDS-SMV), ambos del National Institute of Standards and Technology (NIST) y los resultados fueron analizados y discutidos.

Palabras clave: Riesgo, incendio, modelo, campo, zona.

\section{RESUMÉ}

Risque d'incendie dans une fosse dechets solides - Dans cette article est analysé le risque d'incendie d'une station de traitement des déchets solides urbains, en particulier à la fosse de dépôt de ces déchets. Ont été réalisées simulations de développement de l'incendie en utilisant un modèle de deux zones, le Consolidated Model of Fire and Smoke Transport (CFAST) et un modèle de champ, le Fire Dynamics Simulator and Smokeview (FDS-SMV), les deux de National Institute of Standards and Technology (NIST) et les résultats sont analysés et discutés.

Mot-clé: Risque, incendie, modèle, champ, zone.

\section{ABSTRACT}

Fire risk in a municipal solid waste pit - In this paper is analyzed the fire risk of a plant of urban solid residues, particularly at the pit of deposition of the residues. Simulations of the development of the fire, using a model of two zones, the Consolidated Model of Fire and Smoke Transport (CFAST) and a field model, Fire Dynamics Simulator and Smokeview (FDS-SMV), both from the National Institute of Standards and Technology (NIST), were carried out and the results analyzed and discussed.

Key words: Risk, fire, model, field, zone.

* O texto deste artigo corresponde à comunicação apresentada ao II Congresso Internacional de Riscos e VI Encontro Nacional, tendo sido submetido para revisão em 14-06-2010, tendo sido aceite para publicação em 23-09-2010.

Este artigo é parte integrante da Revista Territorium, n. ${ }^{\circ} 18,2011$, ${ }^{\circledR}$ RIscos, ISBN: 0872- 8941. 
Introdução

A eliminação dos resíduos, a produção de energia e a minimização da poluição são os problemas chave que devem ser abordados na sustentabilidade das cidades do futuro. Num mundo com recursos finitos e em que se testemunha uma explosão demográfica, têm sido feitos muitos esforços para mudar o modo em como as sociedades se desenvolvem, consomem materiais e energia e eliminam os seus resíduos. No caso da llha da Madeira, as autoridades locais optaram por construir uma solução integrada para a valorização/tratamento/ confinamento dos resíduos devidamente articulada com a valorização multimaterial que se chama Estação de Tratamento de Resíduos Sólidos (ETRS) da Meia Serra. A Instalação de Incineração de Resíduos Sólidos Urbanos (IIRSU) é uma das instalações que compõe a Estação sendo a fossa de resíduos o objecto deste trabalho.

Os veículos de recolha do lixo após pesagem entram na nave de recepção e descarregam os resíduos num dos seis pontos de descarga da fossa.

Esta tem a função de recolher os resíduos, servir de stock de alimentação para a incineração, permitindo a continuação da operação sem fornecimento durante uma semana, além de permitir a movimentação dos resíduos e desimpedimento dos pontos de descarga bem como proceder à homogeneização por mistura dos resíduos através de uma das duas garras de manuseamento.

A carga de incêndio existente na fossa resulta dos próprios resíduos para incineração que são resultantes da actividade doméstica, do comércio, da administração pública e da indústria. Genericamente pode dizer-se que os materiais existentes nos resíduos são: papel/cartão, restos de cozinha, vidro, pedras, cerâmica, metais, madeira, plástico, borracha, têxteis, couro, embalagens típicas de uso doméstico com resíduos de óleos, gorduras, produtos de limpeza e matérias solventes.

O modo de armazenamento dos resíduos na fossa tem uma influência predominante na possibilidade de início e desenvolvimento do incêndio. Em fossas profundas, os resíduos podem ser depositados originando uma superfície horizontal que dificulta a propagação do incêndio. Contudo, na maioria dos casos o empilhamento torna-se inevitável, originando flancos verticais ou "paredes" que facilitam a propagação/desenvolvimento de um incêndio comparativamente às superfícies horizontais. As poeiras representam um perigo adicional, potenciado pelas correntes de ar ou trabalhos com ar comprimido originando - levantamento de partículas inflamáveis que quando misturadas com o ar em determinadas concentrações e composição e com a ignição de uma faísca de impacto (acoplamento de mangueira de ar comprimido, bater de portas, batentes da ponte rolante) ou faíscas de origem eléctrica, podem provocar um incêndio na fossa de resíduos.
O incêndio também pode ocorrer devido à auto-ignição do material existente na fossa, sem qualquer influência exterior. Para surgir uma auto-ignição terá que existir matéria inflamável e uma fonte de energia para o efeito. As matérias inflamáveis surgem nos resíduos fornecidos em estado sólido, líquido ou gasoso. Neste contexto torna-se importante a formação de gás, ou seja, a libertação de gás proveniente destes resíduos, provocada por evaporação de solventes, gases propulsores e combustíveis provenientes de recipientes fornecidos (cargas residuais) e produtos de reacções químicas dos componentes dos resíduos fornecidos. A fonte de energia para originar a auto-ignição poderá ter origem nas faíscas provenientes de impactos ou fricção de matérias duras existentes nos resíduos, no aquecimento dos resíduos por fermentação, aquecimento dos resíduos por reacções químicas na fossa (por ex. por metais, nomeadamente dos 3 grupos principais e secundários da tabela periódica, especialmente o alumínio, magnésio e as suas ligas como também aparas de ferro) em reacção com água ou ácidos diluídos.

\section{Descrição da fossa de resíduos e cais de descarga}

A nave Norte do edifício industrial é constituída pela fossa de resíduos e cais de descarga. A fossa apresenta 27,0 $\mathrm{m}$ de comprimento, 12,5 m de largura, 24,5 m de altura e volume de armazenamento de $2880 \mathrm{~m}^{3}$. O cais de descarga permite a transferência dos resíduos dos camiões de recolha para a fossa. A nave apresenta essencialmente três níveis distintos: o cais de descarga, o fundo da fossa e o nível das tremonhas de alimentação da instalação de incineração (fig. 1). O edifício é de construção mista, sendo os pisos em betão armado com algumas paredes em alvenaria de tijolo pintadas a tinta de água, estando a restante estrutura suportada por pilares e vigas metálicas sem protecção ao fogo, as paredes exteriores e cobertura revestidas com chapa ondulada sendo que alguns dos pilares metálicos arrancam da cota de soleira do edifício. Quer a fossa, quer o cais de descarga, possuem cada um, na cobertura, seis exutores para desenfumagem. Cada exutor possui uma área de $1,7 \mathrm{~m}^{2}$, sendo a abertura manual e simultânea para a fossa e/ou cais de descarga. A cabine da ponte rolante é estanque ao fumo, possui painéis de vidro El 90, varridos por cortina de água, e um sistema de desenfumagem mecânico no seu interior. A fossa é protegida por dois monitores de extinção posicionados ao nível das tremonhas de alimentação, um em cada extremidade da fossa. A operação dos monitores de água/espumífero é controlada na cabina da ponte rolante da fossa ou a partir de um segundo posto de combate ao incêndio, no exterior da cabine, com controlo remoto. Cada uma das duas tremonhas de alimentação possui, para a sua própria segurança e para a segurança das áreas vizinhas, um sistema de extinção de espuma de média densidade. 


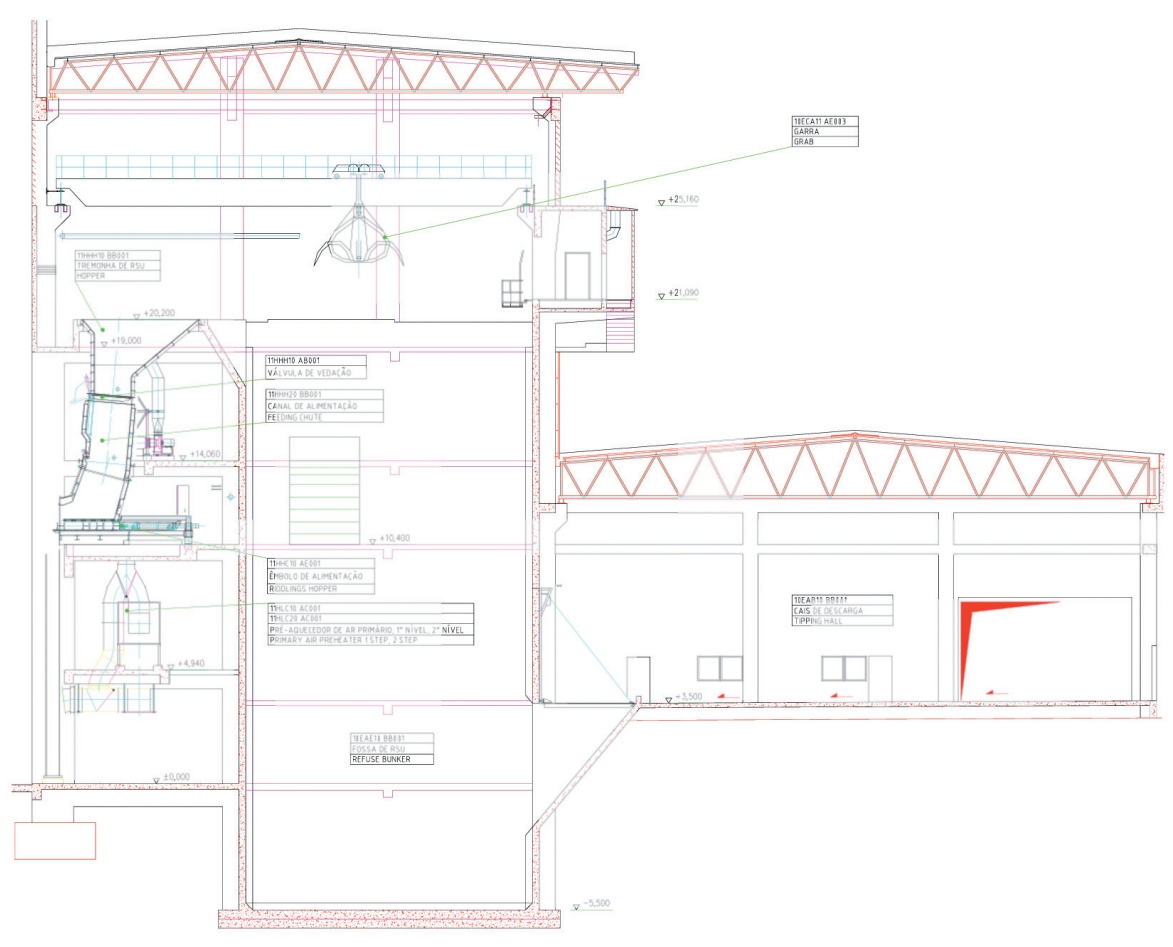

Fig. 1 - Corte longitudinal da nave Norte do edifício industrial: cais de descarga e fossa de resíduos, (ACE ETRS Meia Serra, 2004).

\section{Modelos de Zona e Modelos de Campo}

A modelação de um incêndio num compartimento pode ser feita utilizando modelos de zona (uma ou duas zonas) ou de campo, Computational Fluid Dynamics (CFD). Relativamente aos modelos de zona, são conhecidos diversos, destacando-se o Comprehensive SingleRoom Fire Model (FIRST), o CFAST e o Consolidated Compartment Fire Model (CCFM), desenvolvidos pelo NIST (W. K. CHOW, 1995).

Nos modelos de uma zona os compartimentos são modelados a partir duma só zona que engloba o compartimento enquanto nos modelos de duas zonas os compartimentos são divididos numa camada superior quente e numa camada inferior fria, e as propriedades de cada uma delas, como a temperatura dos gases e as concentrações das espécies são uniformes. A vantagem dos modelos de zona reside na facilidade de utilização e na rapidez do cálculo computacional.

No CFD os compartimentos são decompostos em volumes de controlo elementares, nos quais se prevê a temperatura e os campos de velocidades. A abordagem dos modelos de campo é baseada na resolução numérica das equações básicas da conservação da massa, quantidade de movimento e energia em todo o domínio da solução utilizando o método CFD. 0 modelo de campo fornece informação mais detalhada sobre a propagação do fumo tal como a distribuição da velocidade dos gases, temperatura e concentração de fumo em qualquer parte do domínio. Além disso, o modelo de campo pode ser utilizado para a maioria dos cenários de incêndio, mesmo aqueles com geometria complicada e padrões de fluxo do ar complexos. No entanto, a abordagem da modelação CFD requer grandes recursos computacionais, pelo que é condicionada pelos meios disponíveis. Este é o caso de quando é aplicado à modelação da propagação do fumo de um edifício de diversos andares com vários compartimentos.

O modelo de zona é simples e rápido, mas não fornece resultados precisos na simulação de certos cenários. Por outro lado, a abordagem CFD proporciona uma maior precisão mas exige elevados recursos computacionais. Surge então uma nova abordagem chamada de Modelo Híbrido de Campo e de Zona, Hybrid Field and Zone Model (HFAZM) que combina os modelos de zona e de campo. Neste método, o modelo de zona é aplicado apenas a compartimentos onde a camada estratificada está presente, e o modelo de campo é aplicado a todos os outros compartimentos onde é susceptível a presença de um fluxo vertical forte ou um padrão de fluxo de ar complexo que precise de ser resolvido com precisão como por exemplo, o compartimento de origem e as vias verticais de evacuação. No compartimento de origem foi utilizado um modelo de campo, enquanto para os compartimentos vizinhos recorreram a um modelo de zona. Foram usados os sistemas numéricos tradicionais para resolver as equações diferenciais parciais na parte 
respeitante ao modelo de campo. 0 método de solução das equações diferenciais ordinárias que regem o modelo de zona foi melhorado através de um algoritmo de correcção da pressão que garante a conservação da massa e da energia em cada zona, bem como a equação de estado dos gases. Os resultados da simulação do HFAZM foram comparados com os modelos de zona e de campo com resultados satisfatórios e com menores tempos de computação. As maiores discrepâncias entre os resultados do HFAZM e os obtidos a partir dos modelos de campo parecem estar nos locais onde foi aplicado o modelo de zona, especialmente durante o período transitório inicial da propagação do fumo. Isto será atribuído às limitações do modelo de zona (J. Hua et al., 2005).

\section{Análise da evolução de temperaturas e propagação de fumo na fossa de resíduos}

Para a análise da evolução de temperaturas e propagação de fumo na fossa de resíduos da IIRSU, recorreu-se a dois programas de simulação, o modelo de duas zonas CFAST e o modelo de campo FDS-SMV, ambos do NIST. Além da temperatura superior e inferior da camada de fumo e respectiva altura, por questões de visibilidade por parte do operador, na fossa de resíduos em frente à cabine da ponte rolante, determinaram-se as temperaturas na face exterior do vidro da cabine e nos monitores de extinção, com vista a verificar a sua integridade durante a ocorrência de um incêndio face aos resultados obtidos a partir dos referidos modelos.

\section{Cenários de incêndio}

Os incêndios que surgem na fossa de resíduos na maioria das vezes são detectados precocemente pelos operadores. Com a ajuda das garras, o material em combustão tem de ser apanhado e colocado na tremonha de alimentação, ou seja, deve ser transferido para a câmara de combustão. Ao mesmo tempo que se tenta colocar aquele material na câmara de combustão devem ser accionados os monitores de água/espuma.

\section{Cenário de incêndio 1 (C1)}

Surge um foco de incêndio na fossa de resíduos e passados dois minutos o operador é alertado pelo fumo, transferindo os resíduos em combustão, com a ajuda da garra, para a tremonha de alimentação 1, que é a que se encontra menos cheia. 0 incêndio na fossa continua por não terem sido apanhados todos os materiais inflamados. As seis comportas de descarga, que até então se encontravam abertas, são fechadas pelo alerta do operador, evitando a propagação de fumo para o cais de descarga. 0 fecho das comportas ocorre três minutos após o operador detectar o fumo.

\section{Cenário de incêndio 2 (C2)}

Idêntico ao C1, mas com os seis exutores de 1,70 $\mathrm{m}^{2}$ cada da fossa, abertos ao fim de cinco minutos após a detecção do fumo.

\section{Cenário de incêndio 3 (C3)}

Idêntico ao C2, mas com a comporta de descarga 1 na posição de aberta desde o início do incêndio.

Pretende-se saber também se os resíduos existentes na tremonha 2, que se encontra afastada de 3,7 m da tremonha 1, ganham energia suficiente para se inflamarem. Considera-se que não foram realizadas quaisquer operações de extinção do incêndio durante a simulação (1800 s).

\section{Modelação com o CFAST}

Como se está perante um grande volume, cerca de $18500 \mathrm{~m}^{3}$, há a necessidade de modelar vários subcompartimentos de modo a não serem ultrapassados 1000 $\mathrm{m}^{3}$ em cada um, pois esta é uma condição de aplicação do CFAST (R. D. PeAcock et al, 2005). As paredes das fronteiras em contacto com os vários sub-compartimentos foram consideradas abertas de modo a formar o volume de controlo em estudo. O resultado é o indicado na fig. 2 , onde se encontram também referenciados os vários componentes da fossa de resíduos. Para definição da carga de incêndio foi estabelecido um incêndio numa estação de trabalho, incluída por defeito na biblioteca do programa CFAST e que se indica na fig. 3 .

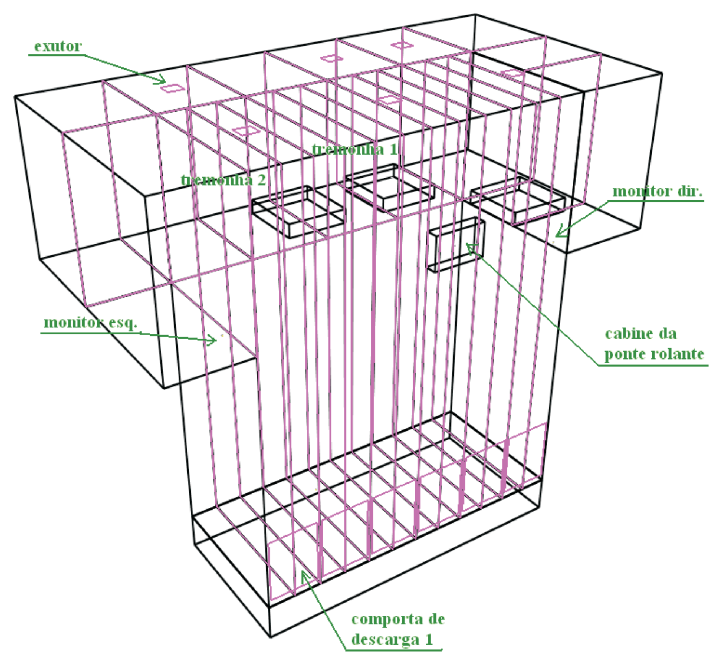

Fig. 2 - Discretização da fossa de resíduos no programa CFAST (NIST). 


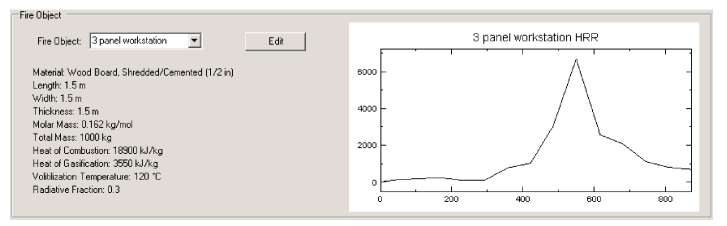

Fig. 3 - Carga de incêndio no programa CFAST (NIST).

\section{Modelação com o FDS}

Na modelação da fossa com o FDS o problema da subcompartimentação já não se coloca, exigindo apenas algum critério na definição da malha, nomeadamente no alinhamento e dimensão (M. KEVIN et al, 2008). Na fig. 4 pode observar-se a modelação considerada, com a criação de cinco malhas devidamente alinhadas. Para definição da carga de incêndio foi admitido que os resíduos existentes na fossa e nas tremonhas de alimentação são constituídos por papel/cartão (40\%), espuma (20\%), vidro (7\%), plásticos $(15 \%)$, metais $(3 \%)$ e madeiras (15\%).

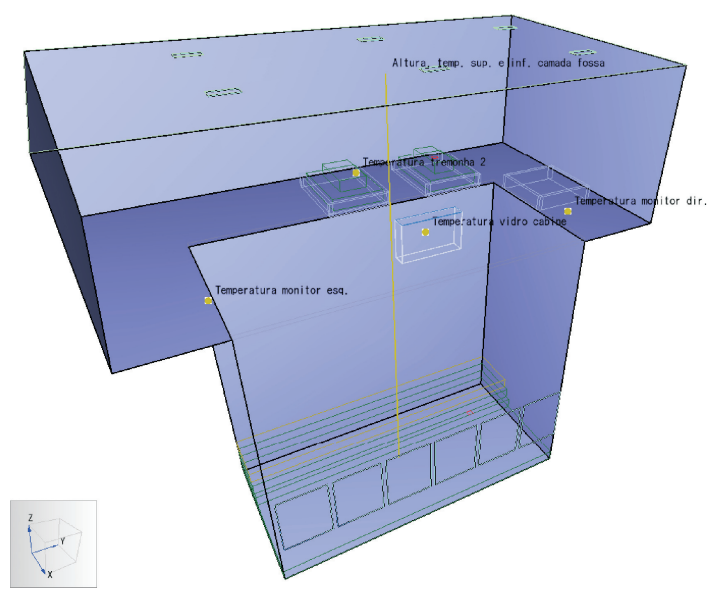

Fig. 4 - Discretização da fossa de resíduos no programa FDS (NIST) (Thunderhead Engineering, 2008).

\section{Resultados dos programas de simulação}

Para o cenário $\mathrm{C} 1$, as temperaturas ao fim de $120 \mathrm{~s}$ e 660 $\mathrm{s}$, obtidas com base no CFAST, podem ser observadas, respectivamente, na fig. 5 e na fig. 6. Nesta última figura é possível observar-se as plumas dos incêndios bem como a temperatura máxima que é verificada no incêndio da tremonha 1. Na fig. 7 pode observar-se, para o cenário C1, a evolução do incêndio obtida com o FDS aos $120 \mathrm{~s} \mathrm{e}$ na fig. 8 aos 1700 s (P. F. GLENN, 2008), verificando-se nesta última figura o encerramento das comportas de descarga, comparativamente à fig. 7 e o volume da fossa francamente enfumado. Os valores resultantes das simulações para os vários cenários e para os dois programas encontram-se esquematizados nas figs. 9 a 15.
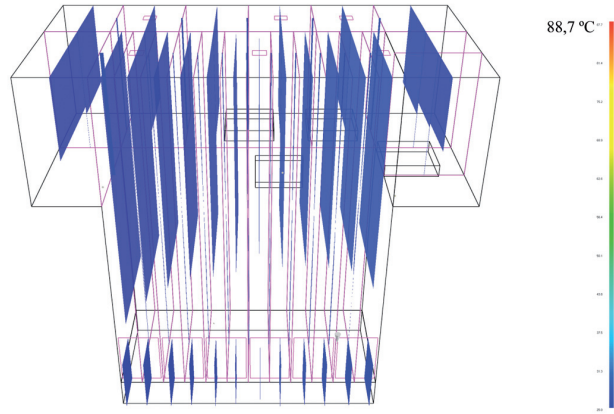

Fig. 5 - CFAST/SMV, C1 aos 120 s (P. F. GLENN, 2008).
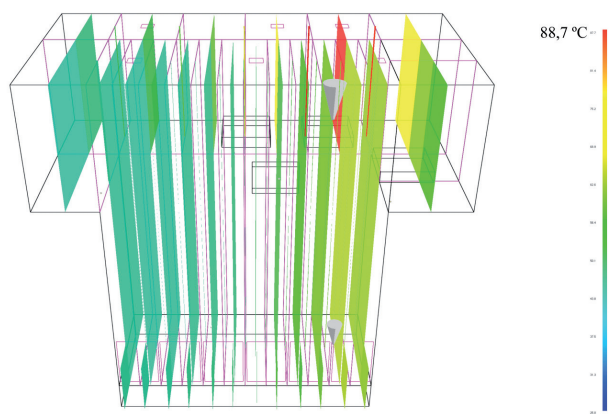

Fig. 6 - CFAST/SMV, C1 aos 660 s (P. F. GLENN, 2008).

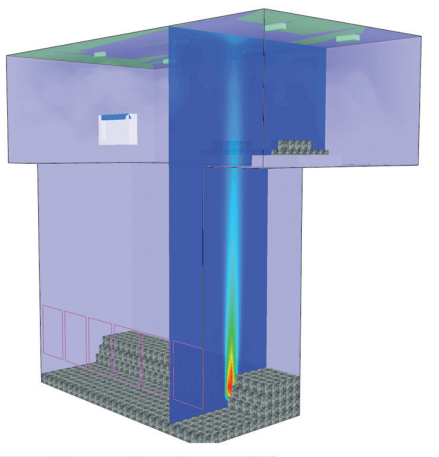

$100^{\circ} \mathrm{C}$

Fig. 7 - FDS/SMV, C1 aos 120 s (P. F. GLeNN, 2008).

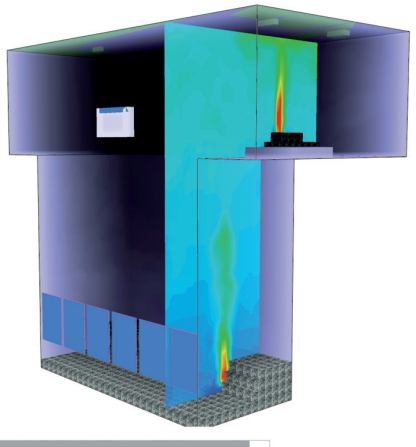

$100^{\circ} \mathrm{C}$

Fig. 8 - FDS/SMV, C1 aos 1700 s (P. F. GLENN, 2008). 
Da fig. 9 verifica-se que no CFAST os três cenários apresentam o mesmo comportamento até cerca dos 7 min, que a abertura dos exutores por si só não impede que todo o volume fique enfumado e que a comporta 1, na posição de aberta desde o início, conjuntamente com a abertura dos exutores na cobertura, permite um varrimento que auxilia a desenfumagem diminuindo assim a altura da camada de fumo.

No FDS verifica-se que essa camada começa a descer aos $4 \mathrm{~min}$, permanecendo uma camada com cerca de $3 \mathrm{~m}$, junto aos resíduos, livre de fumo, e que a abertura da comporta 1 faz diminuir a camada de fumo mas de modo menos pronunciado do que no CFAST.

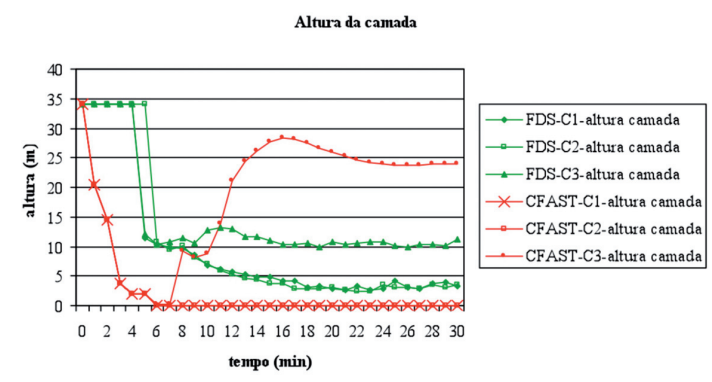

Fig. 9- Altura da camada de fumo em frente da cabine.

Da fig. 10 podemos observar que no CFAST existe um pico de subida de temperatura aos $12 \mathrm{~min}$, para depois se manter estável a partir dos $18 \mathrm{~min}$. No FDS o aumento da temperatura é gradual e ascendente a partir dos 5 min, atingindo um máximo de $40{ }^{\circ} \mathrm{C}$ para os cenários C1 e C2 e estabiliza nos $33{ }^{\circ} \mathrm{C}$ para o cenário C3. 0 pico de temperatura verificado nos três cenários na simulação do CFAST não deixa de ser surpreendente, não se encontrando uma razão específica para tal acontecimento.

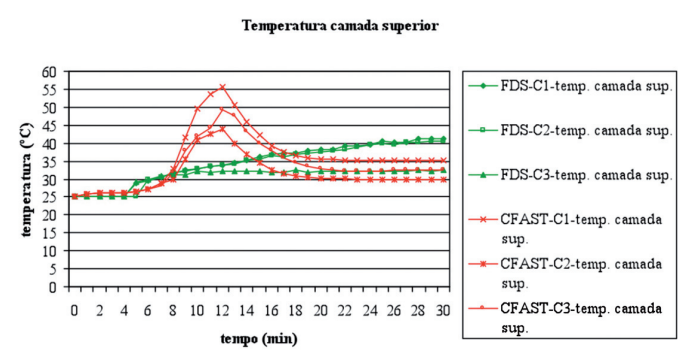

Fig. 10 - Temperatura da camada superior de fumo.

Da fig. 11 verifica-se que no CFAST a temperatura da camada inferior anda muito próximo da temperatura ambiente enquanto no FDS, nos cenários C1 e C2, chegam aos $32{ }^{\circ} \mathrm{C}$ e no cenário $\mathrm{C} 3$ aproxima-se dos 25 ${ }^{\circ} \mathrm{C}$.

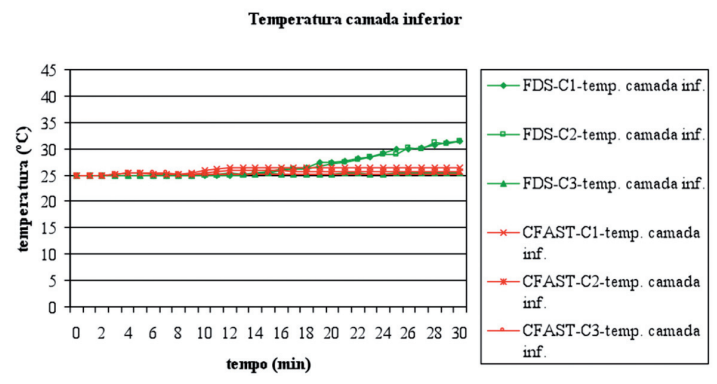

Fig. 11 - Temperatura da camada inferior.

Da fig. 12 verifica-se que no CFAST a subida da temperatura no vidro da cabine começa aos $10 \mathrm{~min}$ não ultrapassando os $31^{\circ} \mathrm{C}$, enquanto no FDS a subida é progressiva e chega aos $40{ }^{\circ} \mathrm{C}$ nos cenários $\mathrm{C} 1$ e C2. No cenário $\mathrm{C} 3$ a temperatura máxima no vidro é inferior e de valor $32{ }^{\circ} \mathrm{C}$.

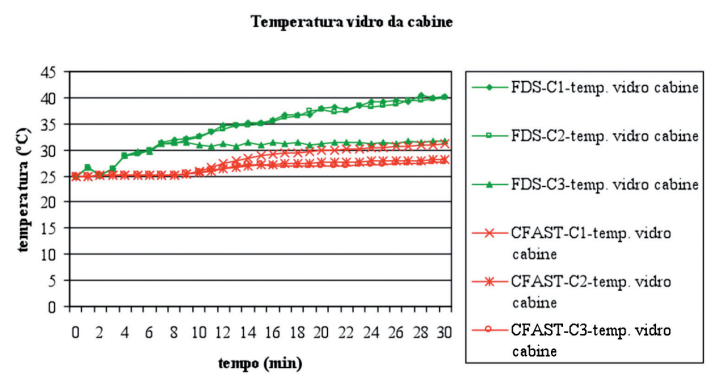

Fig. 12 - Temperatura na face exterior do vidro da cabine.

Da fig. 13 verifica-se que a temperatura no monitor esquerdo é mais baixa no CFAST, começando a subir aos 10 min atingindo o seu máximo de $29^{\circ} \mathrm{C}$ no $\mathrm{C} 1$. No FDS as temperaturas são semelhantes para o $\mathrm{C} 1$ e C2, atingindo um máximo de $42{ }^{\circ} \mathrm{C}$.

Tenperatura monitor esquerdo

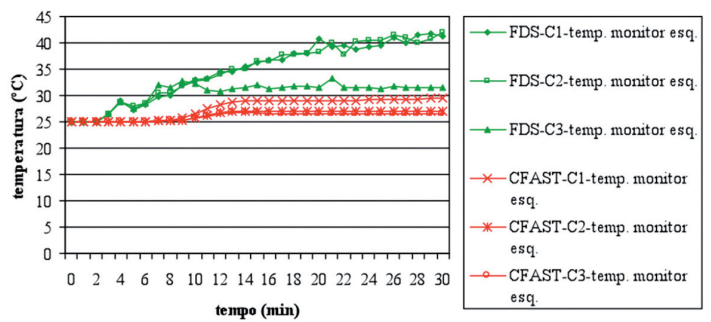

Fig. 13 - Temperatura no monitor de extinção esquerdo.

Da fig. 14 verifica-se que as temperaturas no monitor direito são ligeiramente superiores às ocorridas no monitor esquerdo, visto se encontrar mais próximo do incêndio. 0 desenvolvimento das temperaturas é semelhante ao verificado no monitor esquerdo. 


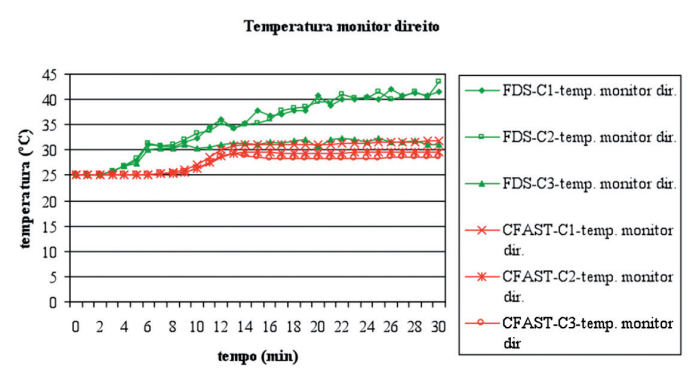

Fig. 14 - Temperatura no monitor de extinção direito.

Da fig. 15 constata-se que o desenvolvimento e o registo das temperaturas na tremonha 2 são semelhantes à dos monitores atingindo o valor máximo na simulação com o FDS para o cenário C2.

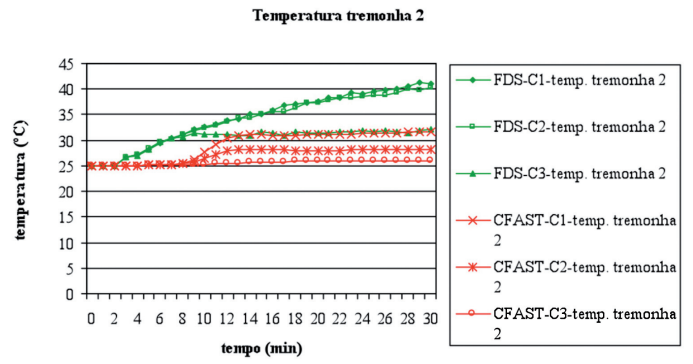

Fig. 15 - Temperatura na tremonha de alimentação 2.

\section{Conclusões}

A modelação do incêndio em edifícios através dos programas de simulação é de extrema utilidade quer na fase de projecto, com o objectivo de serem implementadas as soluções passivas e activas de segurança contra incêndios mais adequadas a cada edifício, quer durante a exploração dos mesmos de modo a responder a perguntas como as que aqui foram formuladas: temperaturas, altura da camada. Para uma análise mais simplificada e mais rápida podemos utilizar os modelos de zona como o CFAST. Para a análise de edifícios mais complexos ou de maior detalhe podemos utilizar os modelos CFD como o FDS que se apresentam mais morosos mas também com outras possibilidades de modelação. No caso concreto apresentado nesta comunicação, conclui-se que as temperaturas na fossa são baixas, mesmo com dois focos de incêndio, devido, sobretudo, ao facto de se tratar de um grande volume onde é fácil a dissipação da energia calorífica. Por norma as temperaturas verificadas no FDS são ligeiramente superiores às obtidas no CFAST. As temperaturas máximas registadas foram no cenário $\mathrm{C} 1$, sendo de $100{ }^{\circ} \mathrm{C}$ no FDS e $88,70{ }^{\circ} \mathrm{C}$ no CFAST. As temperaturas verificadas nos monitores de extinção de incêndio da fossa não serão suficientes para provocar danos que impeçam o seu normal funcionamento em caso de incêndio. Relativamente às temperaturas verificadas na zona da tremonha de alimentação 2 , também não serão suficientes para provocar a inflamação dos seus resíduos, quer por radiação do incêndio na tremonha de alimentação 1 quer por radiação proveniente da camada de fumo. Em termos de visibilidade verifica-se que a saída de fumo por meios naturais só é eficaz se houver entrada de ar fresco com a saída do fumo na fossa, claramente evidenciado nos valores obtidos no cenário $\mathrm{C} 3$, conforme se pode observar na fig.9, pelo que o operador da cabine da ponte rolante terá alguns problemas de visibilidade se forem reunidas as condições dos cenários C1 e C2 aquando de um incêndio real.

\section{Referências bibliográficas:}

CHow, W.K. (1995) - "A Comparison of the Use of Fire Zone and Field Models for Simulating Atrium Smoke-filling Processes", Fire Safety Journal 25, p. 337-353;

GLENN, P. F. (2008) - “User`s Guide for Smokview Version 5 - A Tool for Visualizing Fire Dynamics Simulation Data”, NIST Special Publication 1017-1;

HuA, J. et al (2005) - "Development of hybrid field and zone model for fire smoke propagation simulation buildings", Fire Safety Journal 40, p. 99-119;

KeVIN, M. et al. (2008) - "User's Guide - Fire Dynamics Simulator (Version 5)", NIST Special Publication 1019-5;

Peacock, R. D. et al (2005) - "CFAST - Consolidated Model of Fire Growth and Smoke Transport", Version 6, NIST Special Publication 1041;

Thunderhead Engineering (2008) - "Pyrosim User Manual - A model construction tool for Fire Dynamics Simulator";

XIAOJUN, C. et al (2005) - "A multi-layer zone model for predicting fire behaviour en a fire room”, Fire Safety Journal 40, p. 267-281. 